\title{
Experimental and numerical study of coal-rock bimaterial composite bodies under triaxial compression
}

\author{
Yulong Chen ${ }^{1,2} \cdot$ Jianping $\mathrm{Zuo}^{1,3} \cdot$ Dejun $\mathrm{Liu}^{3} \cdot$ Yingjie $\mathrm{Li}^{3} \cdot$ Zhenbo Wang ${ }^{3}$
}

Received: 10 November 2020/Revised: 5 December 2020/Accepted: 7 January 2021/Published online: 5 February 2021

(C) The Author(s) 2021

\begin{abstract}
To accurately predict coal burst hazards and estimate the failure of coal pillars in underground coal mining systems, it is of great significance to understand the mechanical behavior of coal-rock bimaterial composite structures. This paper presents experimental and numerical investigations on the response of rock-coal, coal-rock, and rock-coal-rock bimaterial composite structures under triaxial compression. The triaxial compression experiments are conducted under confining pressures in the range of 0-20 MPa. The resulting inside fracture networks are detected using X-ray-based computed tomography (CT). The experimentally observed data indicate that the mechanical parameters of the rock-coalrock composites are superior to those of the rock-coal and coal-rock combinations. After compression failure, the coal-rock combination specimens are analyzed via X-ray CT. The results display that the failure of the coal-rock composite bodies primarily takes place within the coal. Further, the bursting proneness is reduced by increasing confining pressure. Subsequently, the corresponding numerical simulations of the experiments are carried out by using the particle flow code. The numerical results reveal that coal is vulnerable with regard to energy storage and accumulation.
\end{abstract}

Keywords Coal-rock bimaterial composite body - Triaxial compression · Strength and deformation · X-ray CT . Numerical simulation · Energy

\section{Introduction}

The number and severity of mine disasters such as roof fall, floor heave, coal-gas outburst, and rockburst severely grow as the mining depth increases (Li et al. 2017, 2020; Lian et al. 2020; Lu et al. 2019; Wang et al. 2019; Wu et al. 2020; Xue et al. 2020; Zuo et al. 2019, 2020a, b, c; Zhao et al. 2018). To reveal the mechanisms of such disasters,

Jianping Zuo

zjp@cumtb.edu.cn

1 State Key Laboratory of Coal Resources and Safe Mining, China University of Mining and Technology, Beijing 100083, China

2 School of Energy and Mining Engineering, China University of Mining and Technology, Beijing 100083, China

3 School of Mechanics and Civil Engineering, China University of Mining and Technology, Beijing 100083, China many investigations were conducted to test the mechanical behavior of individual rock samples (Dou et al. 2020; Guo et al. 2019; Yuan et al. 2018; Zhao et al. 2019; Wang et al. 2020; Shen et al. 2020) or coal samples (Kim et al. 2020; Nikolenko et al. 2020). In fact, these disasters are commonly caused by the failure of the entire coal-rock composite body (Zuo et al. 2013; Zhao et al. 2015; Wang et al. 2017, b). The coal mining field is a combined assembly of the roof rock layer, coal seam, and floor rock layer. The mechanical characteristics of the composite structure play a vital role in coal safety production as well as the safety of coal miners.

Currently, some researches have been conducted on coal-rock bimaterial composite bodies including characterization of their deformation failure under the action of uniaxial compression (Chen et al. 2019). Generally, determination of the mechanical properties of surrounding rock masses from the composite modeling points of view is of great engineering significance (Ju et al. 2018). 
For better understanding coal and rock dynamic disasters during underground mining, this study is devoted to examining the strength and failure of coal-rock bimaterial composites with various combinations, viz., rock-coal, coal-rock, and rock-coal-rock. The coals and rocks are sampled from a colliery in China, which experienced coal bursts, roof falls, and floor heaves due to the low strength of weak soft coal seam as well as the combinational effects of gravity and high ground pressure. The present study is performed by combining uniaxial and triaxial compression experiments at appropriate confining pressures, and thereafter, the X-ray computed tomography (CT) scanning is used. Additionally, equivalent discrete element simulations of the triaxial compression tests are performed to provide further insights into the energy accumulations in various components for examining the energy mechanism in rockbursts.

The roof-coal seam-floor system is gradually regarded as a composite coal-rock body. Some researchers have realized the deformation and strength characteristics of coal-rock bimaterial composites. However, the present study would be unique because of the following reasons: (1) three combination modes are adopted and compared, (2) the number of conducted tests compactly covers the range of confining pressures, (3) the axial compression is applied to obtain the whole stress-strain relationship until arriving at the residual strength, (4) the relationship between the strength and deformation parameters of the coal-rock composite body as well as the confining pressure is derived, (5) CT scanning is carried out to analyze the internal damage characteristics of the specimens after the experiments, (6) the intrinsic bursting proneness of coalrock composite structures is discussed, (7) the corresponding numerical simulations are carried out using the particle flow code (PFC), and (8) the energy accumulations in different components are investigated.

\section{Project overview and geological conditions}

The coals and rocks are taken from Kailuan Qianjiaying coal mine in Hebei Province, China. Because of the softness and friability of the coal seam, large deformations have been produced in the rock around the roadway. Under the combinational effects of gravity and tectonic stresses, large extrusions take place within the coal floor leading to serious floor heave as well as a great danger of coal bursts. Figure 1 demonstrates a typical coal burst in Kailuan Qianjiaying coal mine as well as deformations and failure characteristics of both coal and rock. In this view, simulating the mechanisms of rockbursts in such a mine is of great significance to provide theoretical predictions during

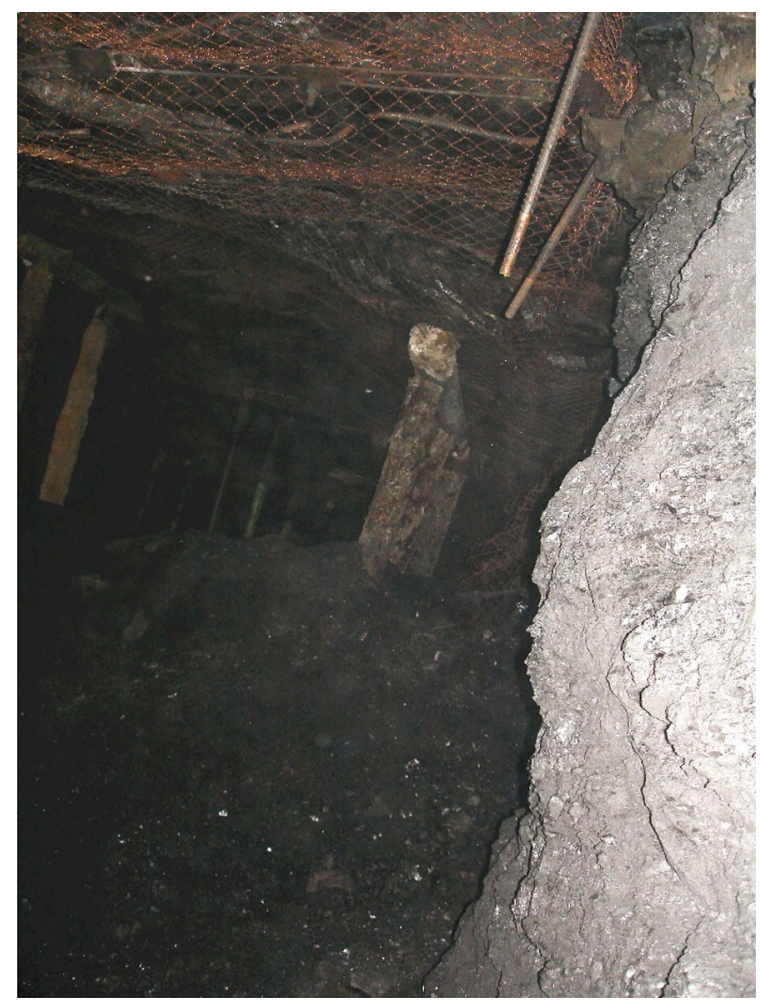

Fig. 1 Coal burst in the Kailuan Qianjiaying coal mine

mining as well as to reduce the risk of production disruption of coal mine.

The annual coal production of the mine is about six million tonnes. The mining lease is $12.7 \mathrm{~km}$ long, has variable width and depth in the ranges of $1.9-6.2 \mathrm{~km}$ and 582-1280 m, respectively, such that it covers an area of about $42.6 \mathrm{~km}^{2}$. Figure 2 presents the overall mining layout and geologic settings of the mine. The coal-bearing stratum of the mine is the Majiagou formation (Middle Ordovician), and there exist six coal seams. The main extraction coal seam is the No. 7 having a $4^{\circ}-18^{\circ}$ dip and a thickness that varies in the range of $0.15-9.23 \mathrm{~m}$. The immediate roof of the seam is a 4-m-thick siltstone, and the main roof is a $2.2-\mathrm{m}$-thick fine sandstone. The immediate floor consists of a 1.4-m-thick siltstone, and the hard floor is a 2.6-m-thick fine sandstone. The local stratigraphic map of the No. 7 coal seam is demonstrated in Fig. 3.

\section{Experimental setup}

\subsection{Materials and specimen preparation}

The coal and rock samples are taken from the No. 2071 working face of the No. 7 coal seam at the approximate depth of $850 \mathrm{~m}$. According to the stratigraphic column, one can see that rock types in both of the roof and floor of the 


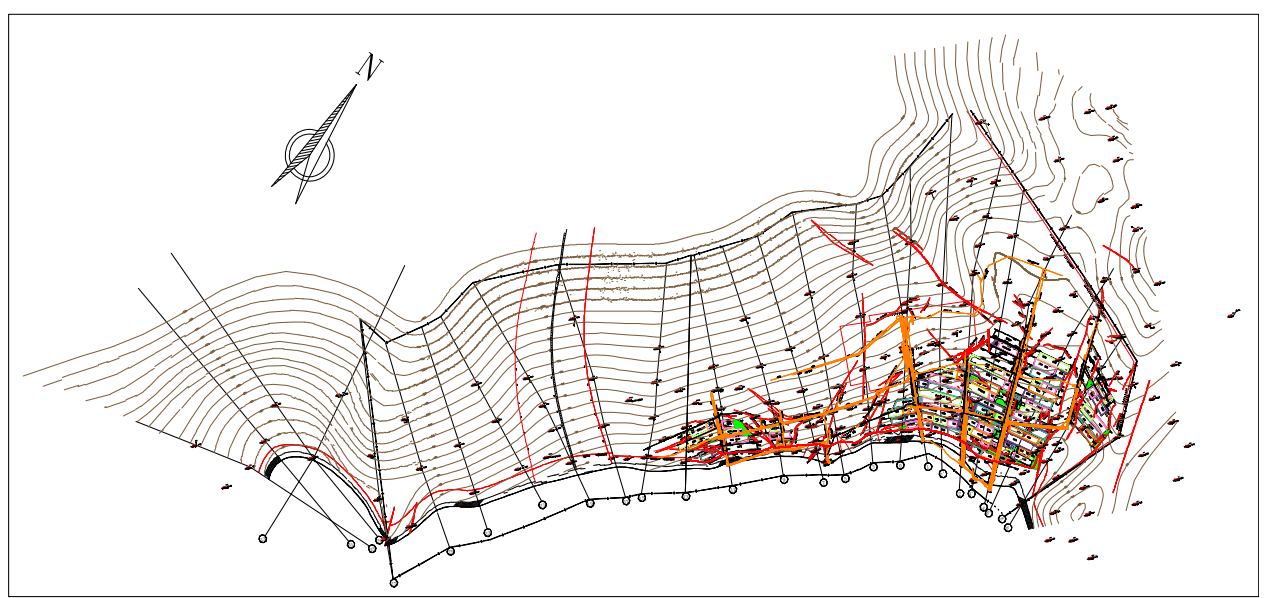

Fig. 2 Layout and geological settings of Kailuan Qianjiaying coal mine

\begin{tabular}{|c|c|c|}
\hline & Thickness (m) & Lithology \\
\hline \multirow{5}{*}{ \#7 } & 2.2000 & Fine sandstone \\
\hline & 4 & Siltstone \\
\hline & $0.15-9.23$ & Coal \\
\hline & 1.4000 & Siltstone \\
\hline & 2.6000 & Fine sandstone \\
\hline
\end{tabular}

Fig. 3 Stratigraphic column of the No. 7 coal seam

No. 7 coal seam are the mixture of siltstone and finegrained sandstone. For simplicity and to ensure the uniformity of the coal-rock bimaterial composite samples, the fine-grained sandstone with favorable homogeneity from the mining site was chosen as the testing rock sample.

Three combination modes, viz., rock-coal-rock, rockcoal, and coal-rock are taken into account to present roof rock-coal-floor rock, roof rock-coal, and coal-floor rock, respectively. The combination modes of the rock-coalrock, rock-coal, and coal-rock are referred as the RMR, $\mathrm{RM}$, and MR, respectively, where $\mathrm{R}$ and $\mathrm{M}$ in order denote the rock and coal. The selected combination modes of the rock and coal are based on the coal seam distributions, as shown in Fig. 4. For instance, the RM and MR combination modes in order are referred to the combination of the rock placed over or below the coal. The coal and rock are polished into $\Phi 35 \mathrm{~mm} \times 35 \mathrm{~mm}$, which are combined into a standard composite medium of $\Phi 35 \mathrm{~mm} \times 70 \mathrm{~mm}$. Concerning the RMR combination mode, the coal and rock are processed into $\Phi 35 \mathrm{~mm} \times 23.3 \mathrm{~mm}$. Two samples of rock are then exploited to sandwich the coal sample, forming a rock-coal-rock composite body having the
Combination mode

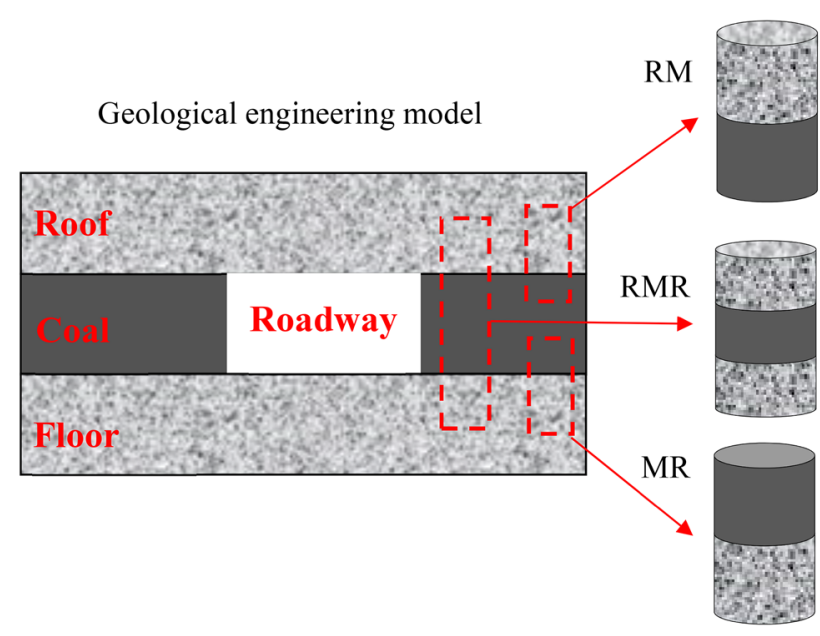

Fig. 4 Schematic diagram of the coal-rock composite structure

overall size of $\Phi 35 \mathrm{~mm} \times 70 \mathrm{~mm}$. As suggested by Zuo et al. (2016), to reduce additional influence factors, the coal part and the rock part contact each other directly without any superglue at the interface. Further, the side face of the composite structure is fixed with scotch tape.

\subsection{Experimental equipment and procedure}

All uniaxial and triaxial compression experimental tests are performed by using the advanced MTS 815 testing machine at Sichuan University, China. During conducting experiments, specimens are installed with a heat-shrinkable tube to prevent oil penetration. Axial loads and axial displacement are measured by a load cell and an axial LVDT. Lateral displacement is measured by two lateral chains transducers placed on the coal and rock.

In order to decrease the effect of the rock heterogeneity on the triaxial test results, repetitive tests are organized for 
three specimens from each group under various confining pressures of $0,5,10,15$, and $20 \mathrm{MPa}$. The displacement loading mode of speed $0.06 \mathrm{~mm} / \mathrm{min}$ is used in both uniaxial and triaxial compression tests. Regarding loading in triaxial tests, the confining pressure increases to the anticipated value at a constant rate of $3 \mathrm{MPa} / \mathrm{min}$, before the deviatoric stress is imposed. The axial displacement is used as the controlling feedback signal.

After performing the compression tests, the specimens are removed from the triaxial cell and placed in the CT machine to scan their interior fractures. A high-resolution $\mu \mathrm{CT}$ with spatial resolution up to $4 \mu \mathrm{m}$ is employed to detect microcracks within the specimens.

\section{Experimental results}

\subsection{Stress-strain curves}

The typical stress-strain relations for coal-rock composite structures are depicted in Fig. 5. The obtained results for characteristic parameters of each specimen have been summarized in Table 1.

As it is seen, all three combination modes exhibit a similar mechanical behavior. The deviatoric stress versus axial strain displays two important features. Firstly, the non-linearity in the initial deformation stage is gradually diminished by increasing of the confining pressure. This is chiefly related to the applied confining pressure to close the microcracks prior to the axial stress exertion (Yang et al. 2012; Yang and Jing 2013). The second main characteristic is the change from brittle to ductile under action of a particular level of the confining pressure. For such a special condition, the post-peak behavior displays a strain-softening manner, which is much different from the brittle drop in uniaxial tests.

\subsection{Strength and deformation parameters}

Based on the provided data in Table 1, the graphs in Fig. 6 have been plotted to show the variations of the elastic modulus and Poisson's ratio of coal-rock composite structures in terms of the confining pressure; further, the presented graphs in Fig. 7 show the trends of the peak strength as a function of the confining pressure. In these figures, the displayed bars show the error range of the measured data. According to Figs. 6 and 7, the rigidity and strength properties of the coal-rock composite bodies are enhanced by increasing of the confining pressure. The peak strength, Poisson's ratio, and elastic modulus of the RMR are generally larger than those of the RM and MR; however, the values of these four factors of the RM and those of the MR are close. A possible reason for the larger values

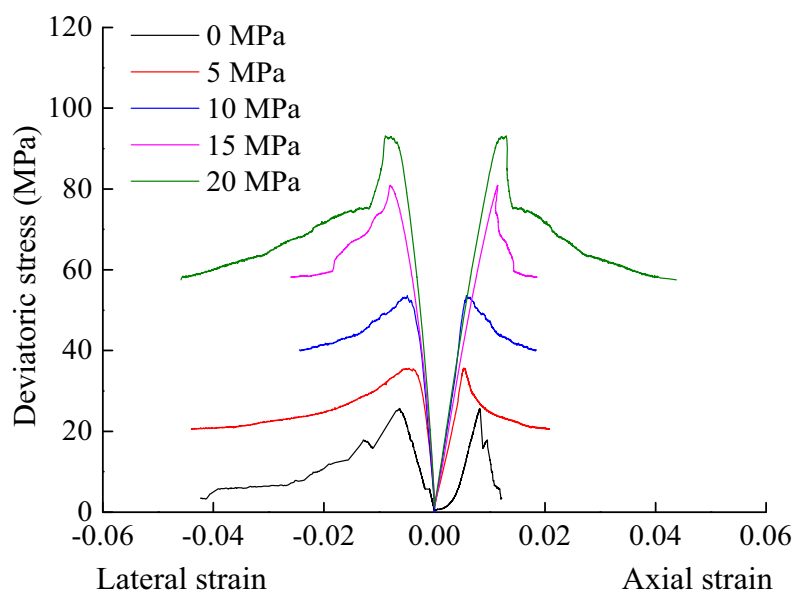

(a) MR

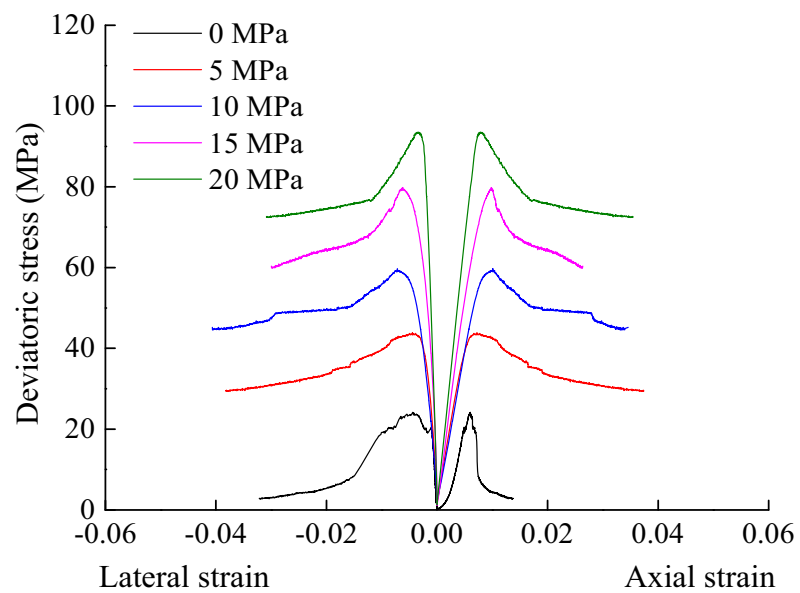

(b) RM

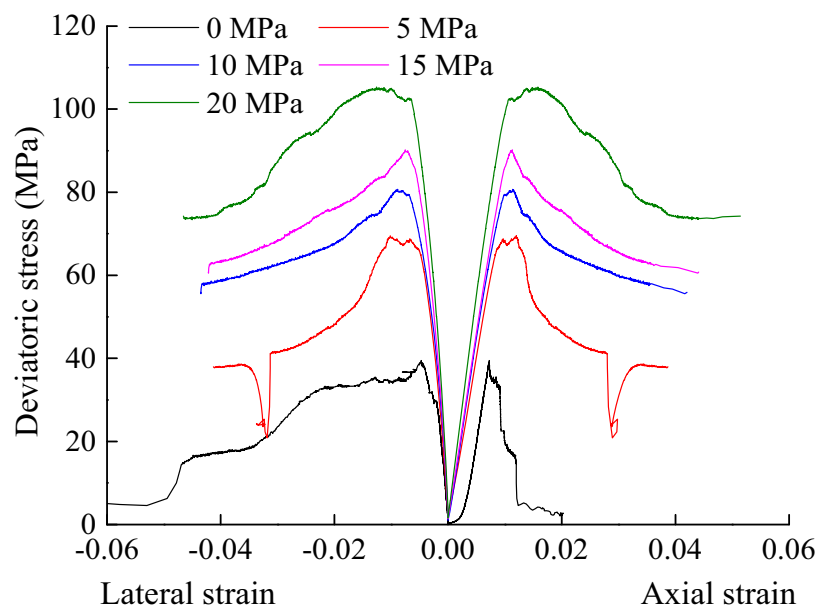

(c) RMR

Fig. 5 Typical stress-strain plots for coal-rock composite bodies

of the strength and deformation parameters of the RMR specimens could be the smaller coal proportion of the RMR 
Table 1 Summary of the experimental results for coal-rock composite bodies

\begin{tabular}{lllll}
\hline Specimen & Confining pressure $(\mathrm{MPa})$ & Elastic modulus $(\mathrm{GPa})$ & Poisson's ratio & Peak strength $(\mathrm{MPa})$ \\
\hline MR & 0 & $6.69,5.33,6.39$ & $0.302,0.345,0.362$ & $23.39,25.44,26.84$ \\
& 5 & $8.71,8.44,8.52$ & $0.388,0.404,0.395$ & $35.67,34.70,35.38$ \\
& 10 & $12.42,12.41,12.51$ & $0.408,0.431,0.430$ & $55.29,57.42,52.38$ \\
& 15 & $15.82,13.20,15.22$ & $0.419,0.460,0.435$ & $80.08,80.95,82.33$ \\
& 20 & $17.15,15.56,16.35$ & $0.423,0.451,0.446$ & $91.90,92.8,90.11$ \\
RM & 0 & $6.37,6.61,5.79$ & $0.324,0.305,0.371$ & $22.74,23.58,23.71$ \\
& 5 & $8.73,8.63,7.46$ & $0.390,0.407,0.398$ & $46.75,43.84,45.86$ \\
& 10 & $12.62,12.12,12.01$ & $0.404,0.426,0.434$ & $56.89,59.70,51.81$ \\
& 15 & $15.54,14.25,14.11$ & $0.418,0.457,0.440$ & $79.81,77.44,78.26$ \\
& 20 & $16.16,17.34,16.76$ & $0.425,0.450,0.451$ & $95.65,90.54,98.15$ \\
RMR & 0 & $7.46,8.16,8.97$ & $0.399,0.408,0.445$ & $39.03,42.34,39.80$ \\
& 5 & $9.33,8.21,9.87$ & $0.418,0.428,0.467$ & $72.43,69.48,65.98$ \\
& 10 & $13.23,14.17,13.68$ & $0.428,0.429,0.479$ & $80.71,83.65,84.25$ \\
& 15 & $15.86,15.41,15.09$ & $0.440,0.475,0.461$ & $90.2,86.85,88.01$ \\
& 20 & $16.63,18.40,17.53$ & $0.478,0.458,0.457$ & $104.47,105.3,107.57$ \\
\hline
\end{tabular}

specimens compared with the RM and MR specimens. The mechanical properties of the rock are much stronger than those of the coal (Zuo et al. 2011a,b). Hence, the mechanical properties of the coal-rock composite body could be controlled by the coal (i.e., the weakest part). A small coal proportion means a lower height/diameter ratio. The strength decreases with the height to diameter ratio of the specimens since the slender specimens provide more possible propagating path for the failure zones (Zhang et al. 2015). Therefore, the RMR specimens with the coal proportion of $1 / 3$ exhibit greater mechanical properties with respect to the RM and MR specimens with coal proportion of $1 / 2$.

The Mohr-Coulomb failure criterion, a linear function of the confining pressure, is employed to express the strength of the specimens. The Mohr-Coulomb criterion is expressed by (Qu and Zhang 2018; Vodička et al. 2018):

$\sigma_{\mathrm{s}}=\sigma_{0}+q \sigma_{3}$

where, $\sigma_{\mathrm{s}}, \sigma_{0}, \sigma_{3}$ in order represent the maximum axial supporting capacity, the uniaxial compressive strength, and the confining pressure, $q$ is an influence coefficient of the confining pressure on $\sigma_{\mathrm{s}}$ of the coal-rock composite structure.

The same relationship can be stated for a Mohr diagram by the straight-line envelope as:

$\tau=c+\sigma \tan \phi$

where, $\tau$ and $\sigma$, the coordinates of the points on the Mohr envelope, in order are the maximum shear stress and the normal stress, acting on the planes with inclination angles $\theta=\pi / 4 \pm \phi / 2$ with respect to the specimen major axis, $c$ and $\phi$ represent the cohesion and the internal friction angle of the coal-rock composite structure, respectively. The values of $c$ and $\phi$ are evaluated as:

$\phi=\arcsin \frac{q-1}{q+1}$

$c=\frac{1-\sin \phi}{2 \cos \phi} \sigma_{0}$

Using the Mohr-Coulomb criterion, the peak strength of the coal-rock composite body has been plotted in Fig. 7a. It exhibits strong nonlinearity of the peak strength under triaxial compression condition (Peng et al. 2014; Bahrani and Kaiser 2013; Long and Li 2018). The peak strength parameters of the coal-rock composite body are also listed in Table 2. The fitting results clearly reveal that both $c$ and $\phi$ of the RMR are the largest among the three combination modes.

\subsection{Macroscopic failure}

The failure modes of the coal-rock composite body specimens under various confining pressures are demonstrated in Table 3, based on which three interesting remarks can be mentioned and discussed. Firstly, damage of the composite body is mainly observed in the coal due to its lower strength. A relatively high amount of accumulated energy is released by coal. The cracking generally occurs more easily in the coal portion subjected to fairly low-stresses.

Secondly, through an increase of the confining pressure, the ultimate failure mode of the coal transmits from the irregular longitudinal splitting tensile failure to the shear 


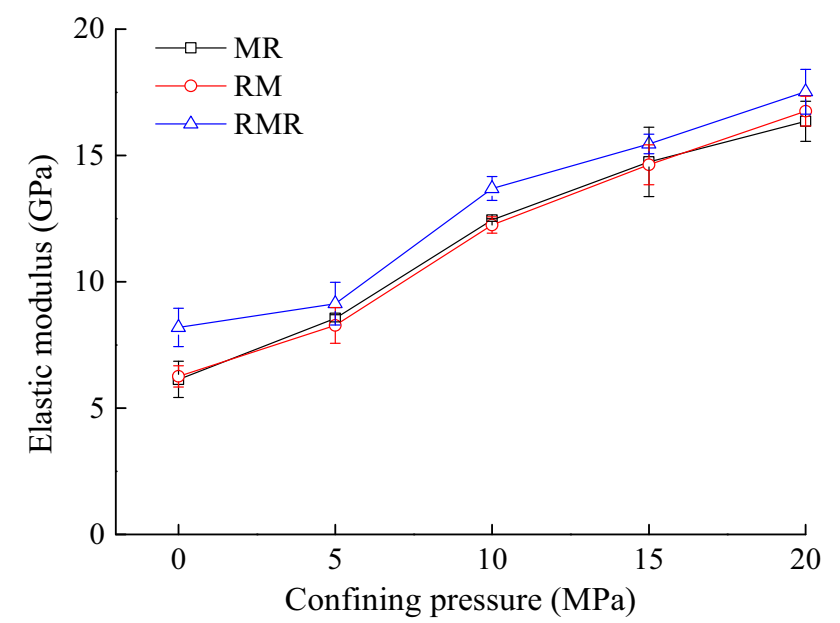

(a) Elastic modulus

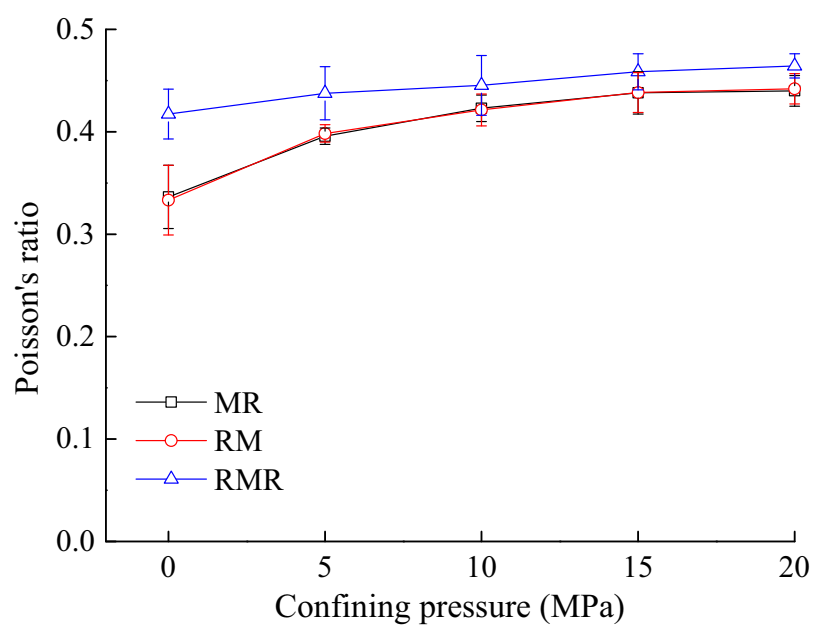

(b) Poisson's ratio

Fig. 6 Variation plots of the elastic modulus and the Poisson's ratio in terms of the confining pressure

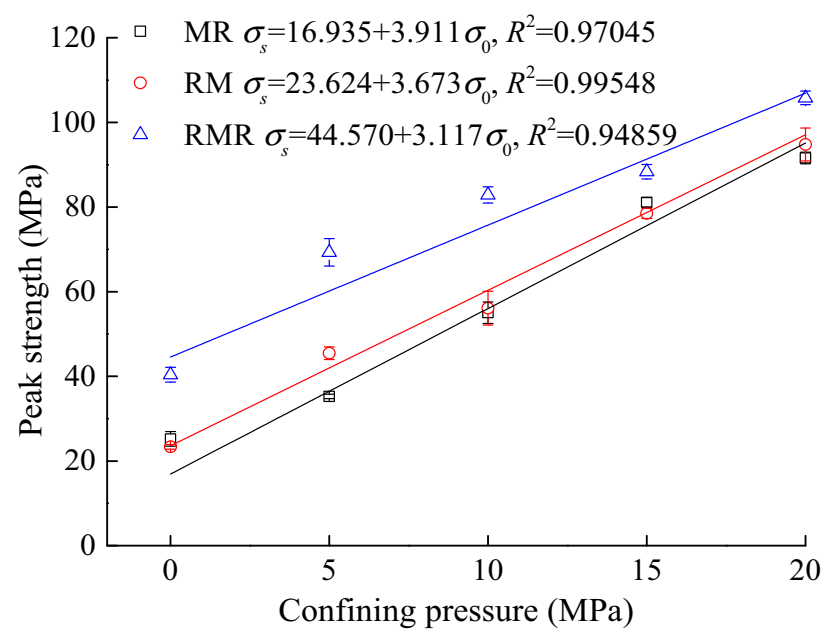

Fig. 7 Variations of the peak strength in terms of the confining pressure
Table 2 Strength parameters of the coal-rock composite body by employing the linear Mohr-Coulomb failure criterion

\begin{tabular}{lllcl}
\hline Combination mode & $\sigma_{0}(\mathrm{MPa})$ & $q$ & $c(\mathrm{MPa})$ & $\phi\left({ }^{\circ}\right)$ \\
\hline MR & 16.935 & 3.911 & 4.28 & 36.4 \\
RM & 23.624 & 3.673 & 6.16 & 34.9 \\
RMR & 44.570 & 3.117 & 10.53 & 39.4 \\
\hline
\end{tabular}

failure. Under the low confining pressure circumferences, the induced cracks are arbitrarily distributed within the coal, and the coal failure is substantially resulted from the induced cracks parallel to the loading direction. On the contrary, at relatively high confining pressures, the induced cracks are commonly accumulated along the shear plane.

Thirdly, cracks preferentially developed in the coal is observed to propagate towards and expand into the rock through the interface between the rock and coal. Hence, the failure of the rock is triggered by the extension of cracks initiated in the coal and propagating into the rock.

\subsection{Microscopic failure}

The CT images of the coal-rock composite specimens at $\sigma_{3}=0,10$, and $20 \mathrm{MPa}$ are also presented to explore the internal damage mechanism. Figure 8 shows the horizontal and vertical cross-section of the specimens after the compression test. The number of microcracks produced within the coal is reduced by increasing of the confining pressure. The internal damage extent of the specimens under uniaxial compression and lower confining pressure is much larger than that under higher confining pressures due to the inhibition effect of the confining pressure on the fracture propagation. That is to say, the confining pressure inhibits the fractures to develop.

\subsection{Bursting proneness}

The bursting proneness is an intrinsic characteristic of the coal. It is usually used to evaluate the risk of coal bursts by assessing its energy accumulation capability. The bursting energy index $\left(K_{\mathrm{E}}\right)$ is adopted to evaluate the bursting proneness of coals (Singh 1988; Cai et al. 2016; Wang et al. 2017). Based on the current standard in China (GB/ T25217.2 2010a, b), the intrinsic bursting proneness is classified into three groups: no bursting proneness $\left(K_{\mathrm{E}}<1.5\right)$, low bursting proneness $\left(1.5 \leq K_{\mathrm{E}}<5\right)$, and high bursting proneness $\left(K_{\mathrm{E}} \geq 5\right)$.

As shown in Fig. 9, the bursting energy index $\left(K_{\mathrm{E}}\right)$ represents the ratio of the accumulated strain energy before the peak strength to the released strain energy after the peak strength. A larger value of $K_{\mathrm{E}}$ means a higher intrinsic 
Table 3 Failure patterns of the coal-rock composite specimens under different confining pressures

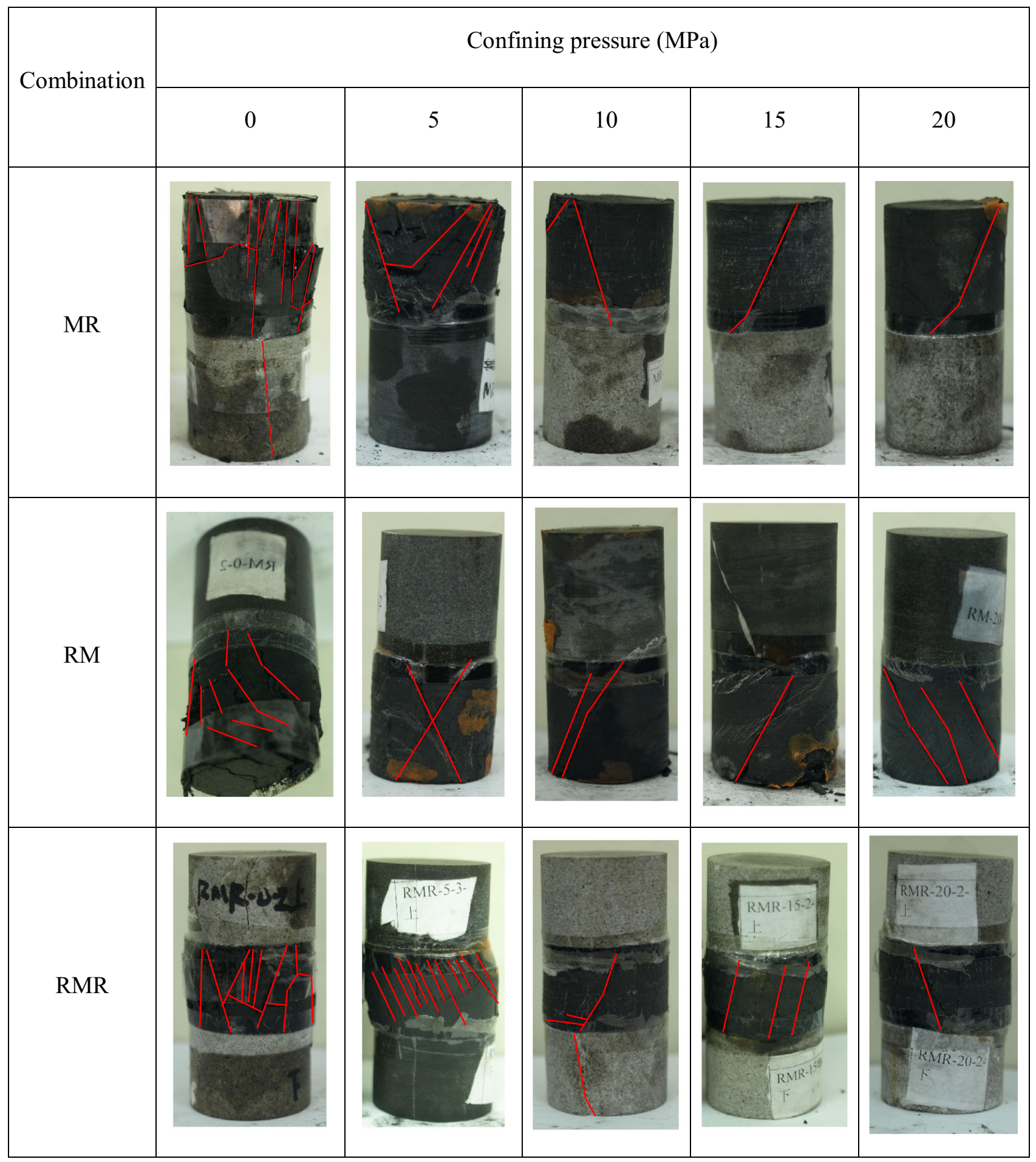

bursting proneness of the coal. The values of the bursting energy index of coal-rock composites for each specimen are calculated and plotted in Fig. 10.

The trend of the decreasing bursting energy index with increasing of the confining pressure is observed in all cases for the coal-rock composites. Such a reduction in the bursting energy index is associated with the brittle-ductile mechanical behavior transition with an increase of the confining pressure. As presented in the stress-strain curves, the plastic behavior of the coal-rock composites is sensitive 


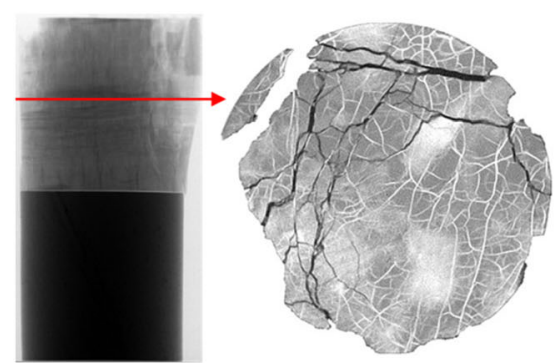

$\sigma_{3}=0 \mathrm{MPa}$

(a) MR

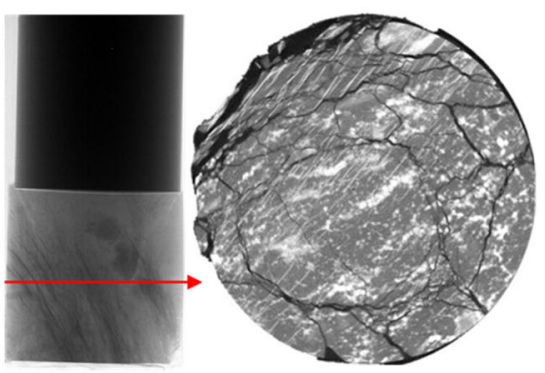

$\sigma_{3}=0 \mathrm{MPa}$

(b) RM
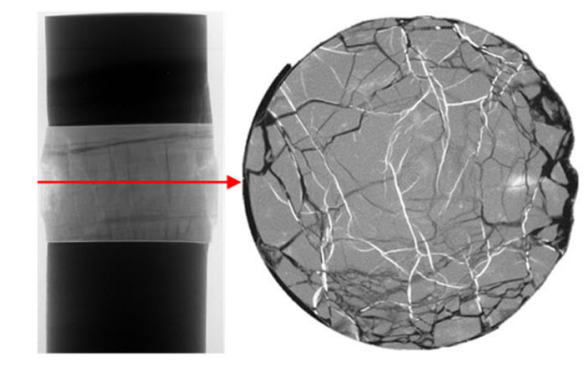

$\sigma_{3}=0 \mathrm{MPa}$

\section{(b) RM}
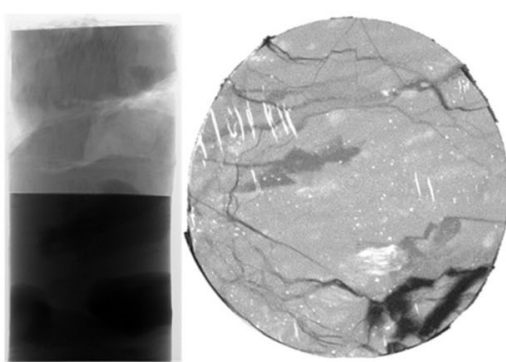

$\sigma_{3}=10 \mathrm{MPa}$
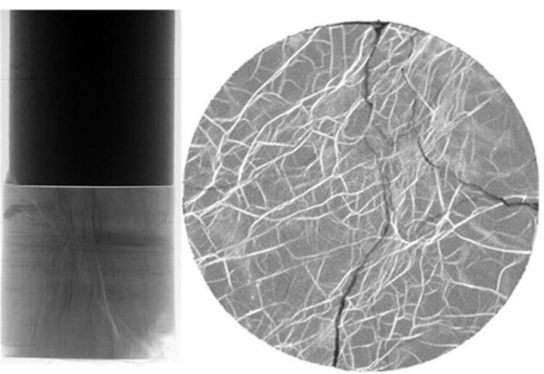

$\sigma_{3}=10 \mathrm{MPa}$
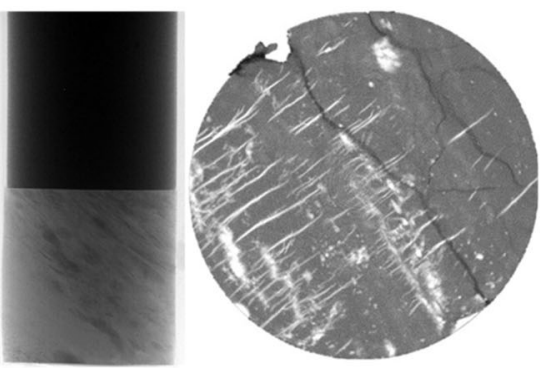

$\sigma_{3}=20 \mathrm{MPa}$

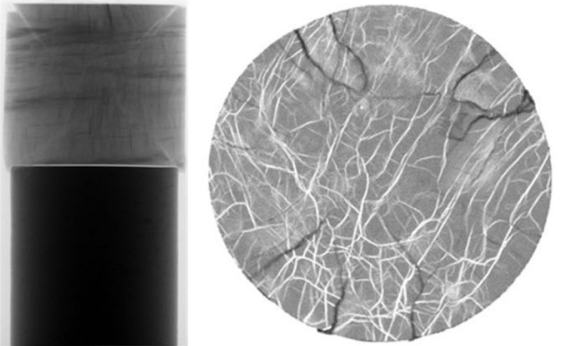

$\sigma_{3}=20 \mathrm{MPa}$
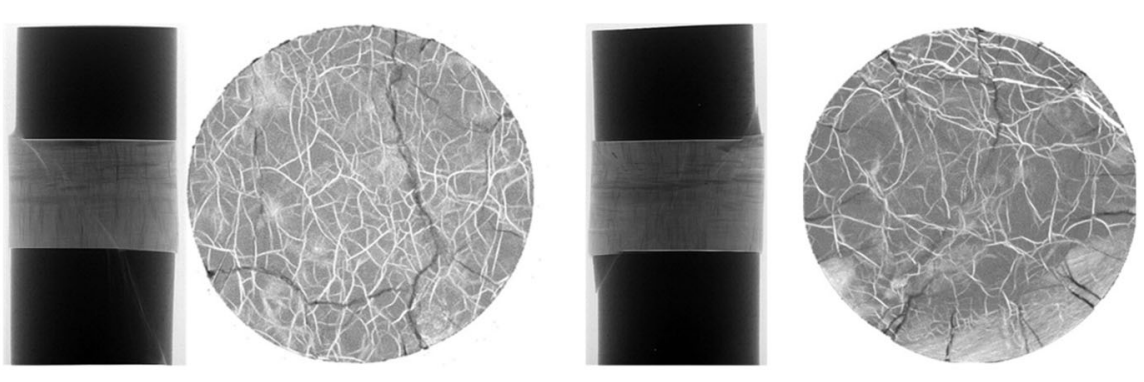

(c) RMR

Fig. 8 CT images of the specimens after the triaxial test

to the confining pressure, and the brittle-ductile transition of the mechanical behavior is detectable when the confining pressure increases. The increasing of the confining pressure on the specimens alters the deformation regime in the post-peak state from "a brittle drop in stress" to "strain-softening". The stress drop rate decreases and has a gentler trend by increasing of the confining pressure. Further, the mechanical characteristics of the rock mass in the post peak zone have a crucial influence on the stability control of the surrounding rock mass, especially in longwall mining as well as the design of mine pillars (Bieniawski 1984).

Based on the measured indices of the bursting energy, the coal-rock composite structure has a low bursting proneness in uniaxial compression, and no bursting proneness under triaxial compression, indicating that confining pressure restricts lateral deformation and enhances load-bearing capacity. This fact is also in good agreement with the failure modes when there is confining pressure. Consequently, the confinement could reduce the bursting 


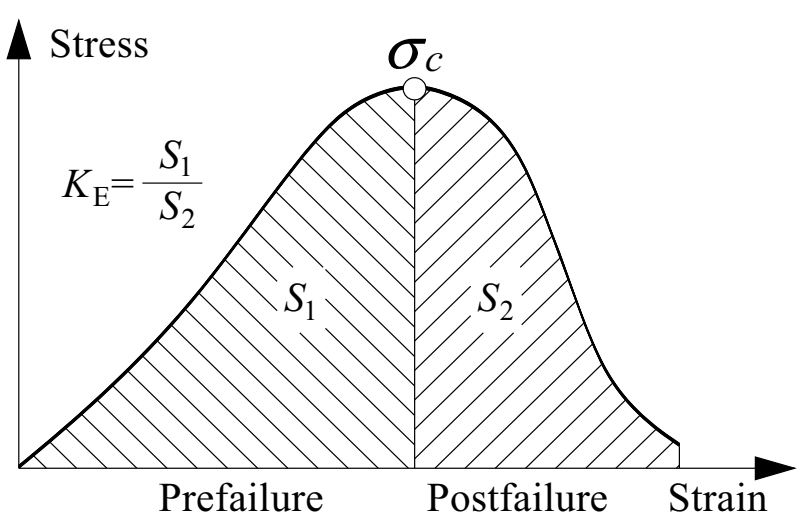

Fig. 9 Parameters used in definition of the bursting energy index

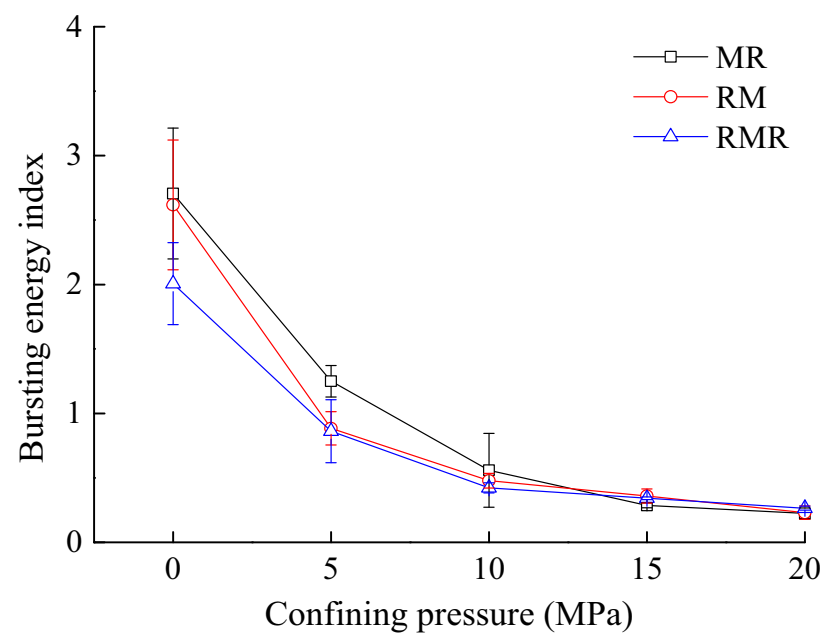

Fig. 10 Relationship of the bursting energy index of the coal-rock composite as a function of confining pressure

proneness of both coal and rock. In other words, the likelihood of coal bursts at deeper depths would be greater compared to that at shallow depths. However, stress redistribution takes place during the excavation process. The high elastic energy accumulation pertinent to the extraction of coal as well as its corresponding stress redistribution increases the proneness of coal bursts.

\section{Numerical simulations}

In the present research work, all laboratory triaxial compression tests are conducted blind, as the samples are sealed in an opaque heat-shrinkable tube as well as placed in the confining pressure cylinder. The displacements of the coal-rock combination samples refer to the total displacements of the composite body; however, the displacement of the coal or the rock cannot be identified individually. In an attempt to more fully understand the deformation and bursting energy properties of the coal-rock composite structure, a series of numerical simulations corresponding to the laboratory experiments is performed.

\subsection{Model construction and modeling schemes}

The PFC2D is used for the numerical modeling and providing further insights into the intrinsic bursting proneness of coal-rock composite acted upon by the triaxial compression. The numerical specimens have the same sizes as the experimental specimens, consisting of 6932 particles. The triaxial compression model is built using parallel bonds and the connection between the coal and the rock is cohesionless. According to the macro-properties obtained from experiments on the single coal and rock conducted by Chen et al. (2019), the micro-parameters of the numerical specimen are calibrated, and then, tabulated in Table 4. The confining pressure is applied in the horizontal direction and the axial load is controlled by applying displacement at the top of the specimen.

\subsection{Numerical results}

Figures 11, 12 and 13 show the numerical stress-strain curves, strength and the failure modes of coal-rock composite specimens under triaxial compression at different combination modes and confining pressures. It can be observed that the numerical results agree well with those of the experiment. Similar to the experiments, the signs of the transition from the brittle to the ductile with increasing the confining pressure in the post-peak is observed (Fig. 11). Additionally, the peak strength values obtained from the simulations are in good agreement with those from the carried out experiments (Fig. 12). Moreover, the numerical and experimental failure modes of the coal-rock composite specimens are highly consistent, featuring splitting tensile

Table 4 Microscopic parameters of models

\begin{tabular}{lll}
\hline Parameter & Coal & Rock \\
\hline Minimum particle diameter $(\mathrm{mm})$ & 0.3 & \\
Particle diameter ratio & 1 & \\
Porosity & 0.2 & \\
Friction coefficient & 0.5 & \\
Damping ratio & 0.7 & 30 \\
Elastic modulus $(\mathrm{GPa})$ & 3 & 0.3 \\
Poisson's ratio & 0.33 & 26.32 \\
Cohesion (MPa) & 6.74 & 25.6 \\
Internal friction angle $\left(^{\circ}\right)$ & 20.82 & 23 \\
Dilatancy angle $\left(^{\circ}\right)$ & 18.5 & \\
\hline
\end{tabular}




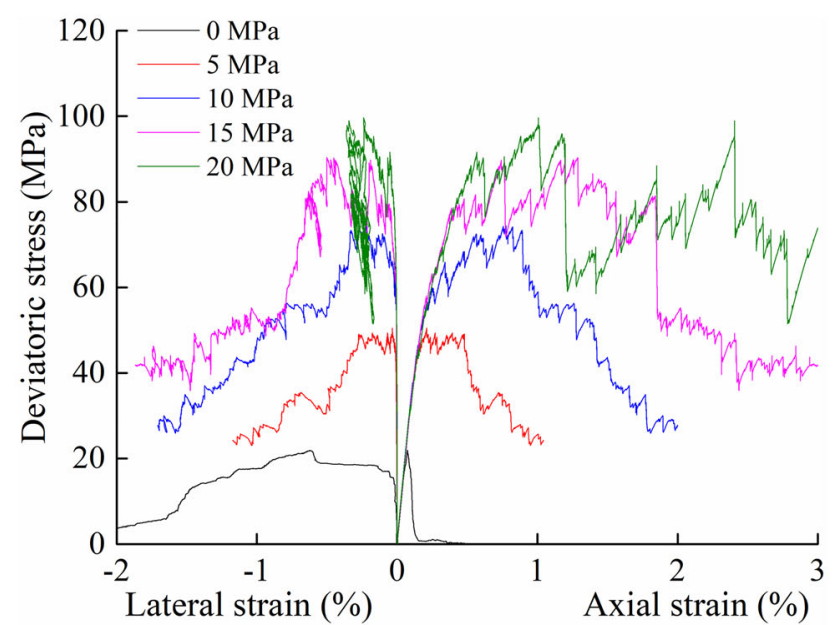

(a) MR

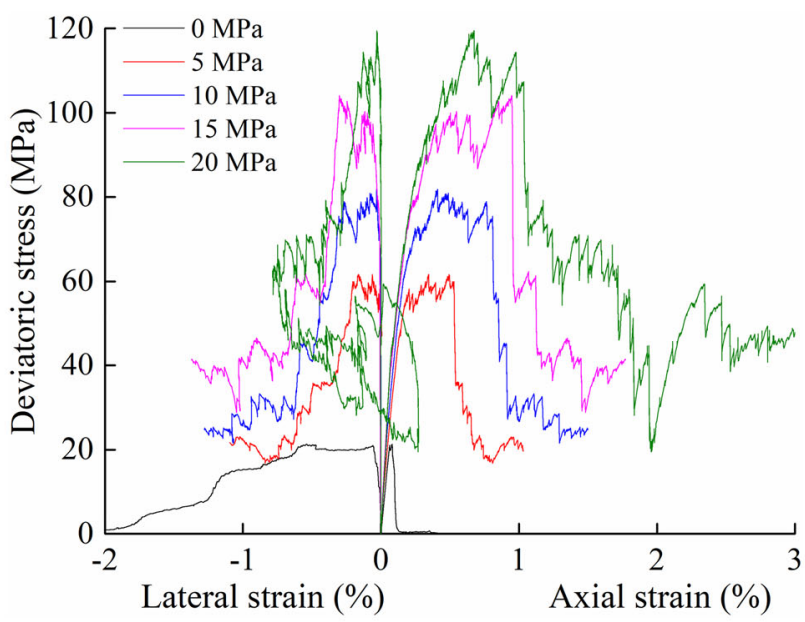

(b) RM

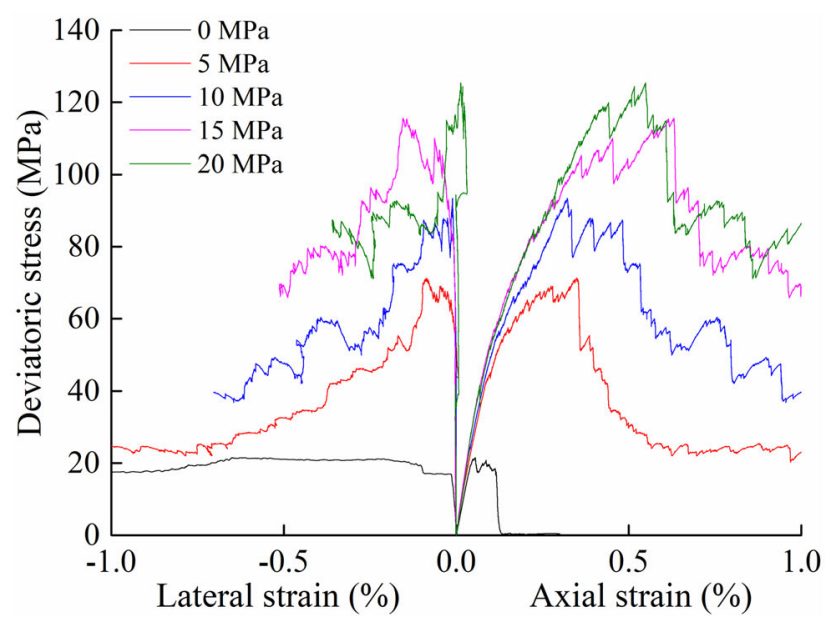

(c) RMR

Fig. 11 Numerical stress-strain curves of the coal-rock composite specimens failure under both uniaxial compression and lower confining pressure as well as shear failure under higher confining pressure (Fig. 13). It should be noticed that most fractures occur in the coal and few are observed in the rock. Besides, the cracks extend from the coal into the rock through the interface, leading to the overall destruction of the combination.

\subsection{Energy mechanism}

Rockbursts are rapid and violent spalling of rocks driven by energy; it results from the combination of accumulation and transformation of strain energy. Under uniaxial compression, only axial stress acts on the rock. The absorbed energy can be calculated as follows (William 2013; Xie et al. 2009):

$U_{\mathrm{u}}=\int_{0}^{\varepsilon_{1}} \sigma_{1} \mathrm{~d} \varepsilon_{1}$

Under triaxial compression conditions, both axial stress and confining pressure act on the rock:

$U_{\mathrm{t}}=\int_{0}^{\varepsilon_{1}} \sigma_{1} \mathrm{~d} \varepsilon_{1}+2 \int_{0}^{\varepsilon_{3}} \sigma_{3} \mathrm{~d} \varepsilon_{3}$

where $U_{\mathrm{u}}$ and $U_{\mathrm{t}}$ represent the energy absorbed from the unconfining and the confining components, respectively; $\sigma_{1}$ and $\varepsilon_{1}$ in order are the axial stress and strain, while $\sigma_{3}$ and $\varepsilon_{3}$ denote the confining pressure and the lateral strain, respectively.

In all numerical simulations, the measurements of stress and strain of individual coal and rock are automatically and continuously implemented. Accordingly, the strain energy of coal $\left(U_{\text {coal }}\right)$ and the rock $\left(U_{\text {rock }}\right)$ could be calculated. Figure 14 demonstrates the evolution of the strain energy of the coal $\left(U_{\text {coal }}\right)$ and that of the rock $\left(U_{\text {rock }}\right)$ in a complete stress-strain process under various confining pressures and combination modes. It can be seen that most of the absorbed energy is accumulated in the coal (i.e., only a small amount of energy is absorbed in the rock). This is because of the more significant axial and lateral strains of the coal compared with those of the rock.

\section{Discussion and limitation}

(1) The stress state of coal and rock at the interface is shown in Fig. 15. The Poisson's ratio of coal exceeds that of rock. Thus, the lateral deformability of coal is greater than that of rock, which causes a horizontal compressive stress on coal and a horizontal tensile stress on rock at the interface. Tensile cracking tends to occur in the rock at the interface as a result of the end effect. This may explain the propagation of cracks generated from the coal into the 


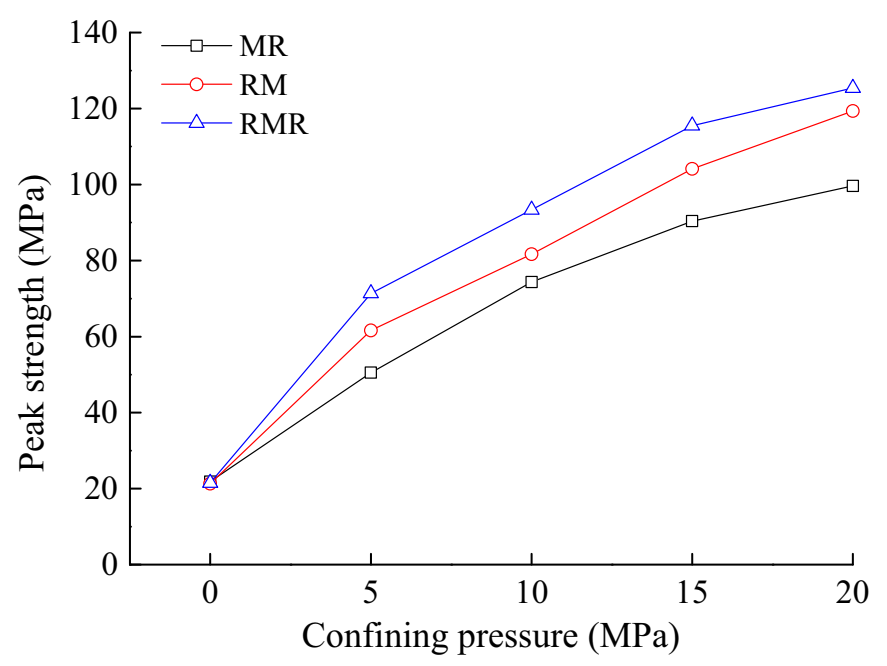

Fig. 12 Numerical strength of the coal-rock composite specimens

rock. Such phenomenon is consistent with previous studies (Liu et al. 2015; Chen et al. 2019, 2020; Zhang et al. 2018).

(2) The surrounding rocks around the roadways of the coal are basically composite structures composed of weakly cemented soft coals and hard rocks and the stability of the roadway is strictly associated with the mechanical behavior of such a composite body. The analysis of the triaxial compression experiments, CT observations, and numerical simulations enable us to examine how the fracture as well as the deformation characteristics could be affected by the coal mass.

We have previously described the strength and deformation behavior of the MR and RM combination modes under uniaxial compression (Chen et al. 2019). This study extends that work to the RMR combination mode besides the MR and RM under triaxial compression.

However, this study does not take into account the effects of the mining layouts. The occurrence of the coal and rock dynamic disasters is directly related to the coalrock interactions, but it also relies on the geological and mining conditions as well as the in-situ stress regime. Generally, the excavation leads to disturbing the balance of the initial equilibrium of the geostress state of the coal seams, thus, geostress distribution as well as its corresponding deformation is modified. Examining the effect of the mining-induced stress evolution processes is also suggested for future work.

(3) The overlying strata of the working face bearing the majority of accumulated energy are referred to as the key energy strata; moreover, these strata dominate rock movements locally or completely. The results of this study suggest that in the composite coal strata consisting of different materials with various hardness, the hard strata with great strength may bear more stress, but they are rarely deformed and exhibited a low energy storage. It is difficult to accumulate energy. In the soft strata with a low strength, the energy could be easily stored and accumulated. Accordingly, the soft strata are key strata with regard to their energy accumulation and they dominate the overall rock burst occurring.

\section{Conclusions}

The stability of roadways in coal seams at excessive mining depth importantly relies on the failure behavior of the coal-rock bimaterial composite bodies under the action of great stresses. To systematically study the failure behavior of the coal-rock composites, both experimental and numerical triaxial compression tests are carried out at confining pressures up to $20 \mathrm{MPa}$. Besides, the CT observation indicates on the specimens to provide a direct insight into the fracture structure after compression. Thereafter, the intrinsic bursting proneness of the three combination modes is examined in some detail. Finally, the corresponding numerical simulations of the experiments are performed. The proportion of the accumulated energy in coal and rock was further investigated. The main results obtained are summarized as:

(1) The elastic modulus, Poisson's ratio, peak strength of the coal-rock composite structure would increase by increasing the confining pressure. Further, these parameters as well as the cohesion and the internal friction angle of the rock-coal-rock combination are reported to be larger than those of the rock-coal and the coal-rock combinations. 


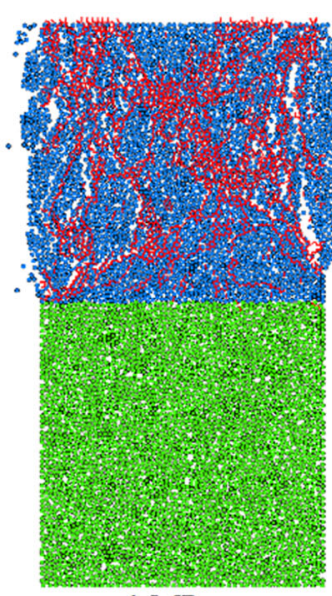

$0 \mathrm{MPa}$

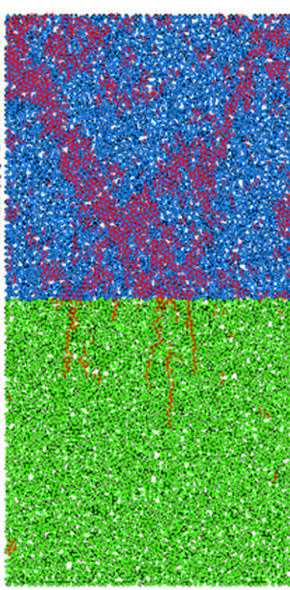

$5 \mathrm{MPa}$

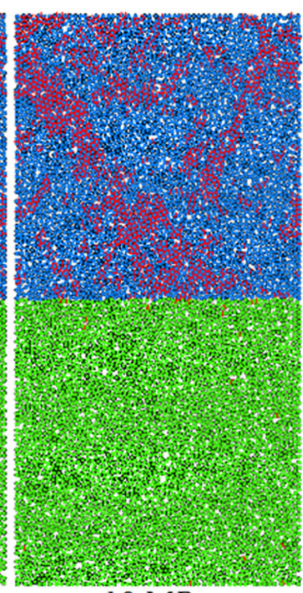

$10 \mathrm{MPa}$

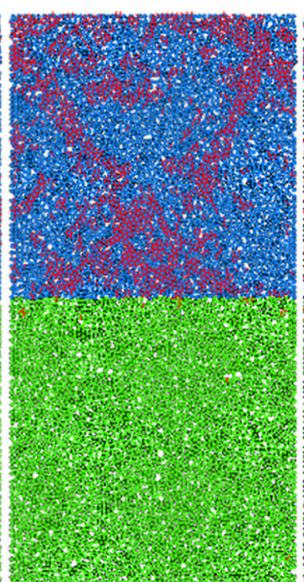

$15 \mathrm{MPa}$

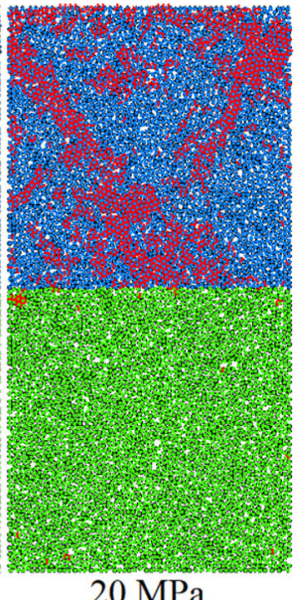

$20 \mathrm{MPa}$

(a) MR

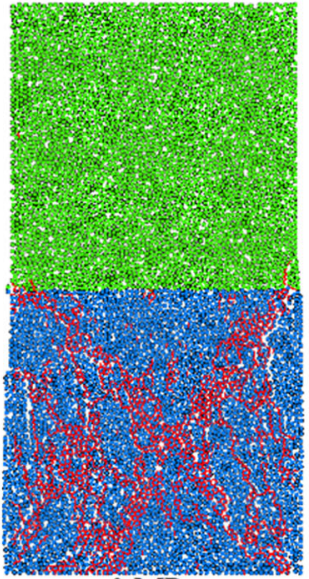

$0 \mathrm{MPa}$

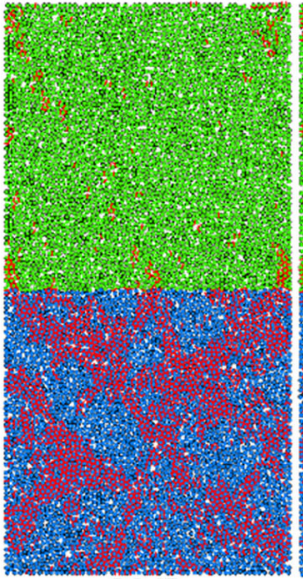

$5 \mathrm{MPa}$

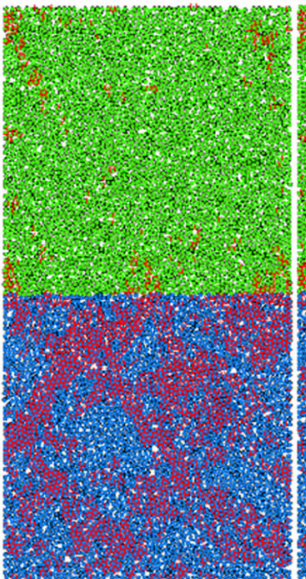

$10 \mathrm{MPa}$

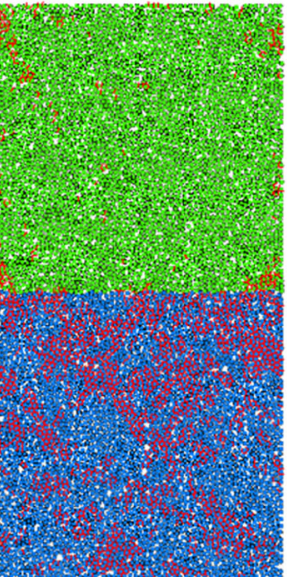

$15 \mathrm{MPa}$

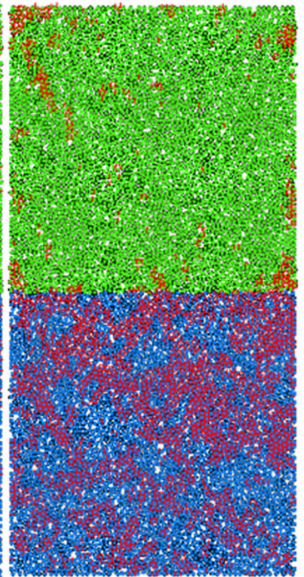

$20 \mathrm{MPa}$

(b) RM

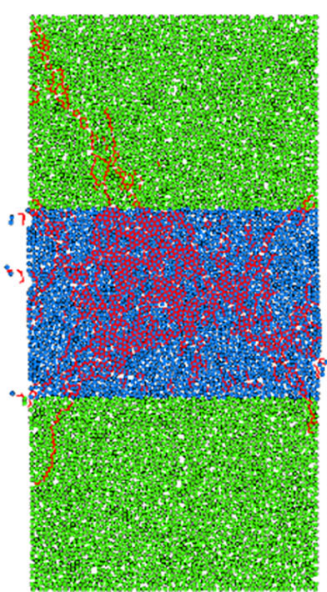

$0 \mathrm{MPa}$

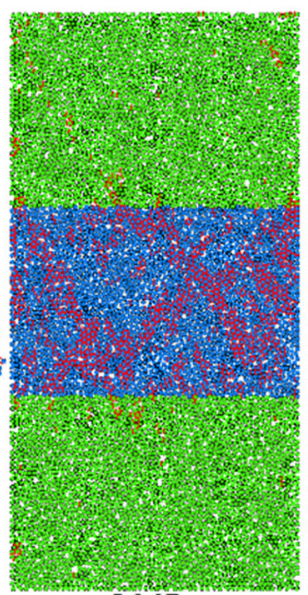

$5 \mathrm{MPa}$

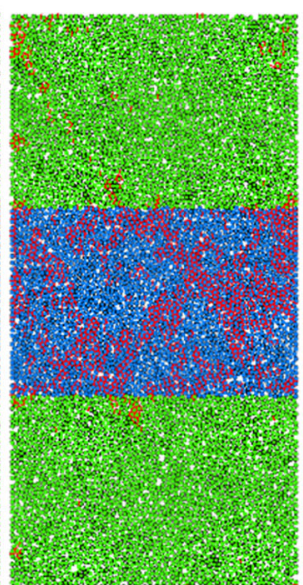

$10 \mathrm{MPa}$

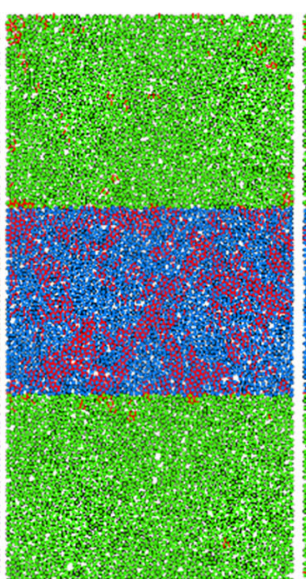

$15 \mathrm{MPa}$

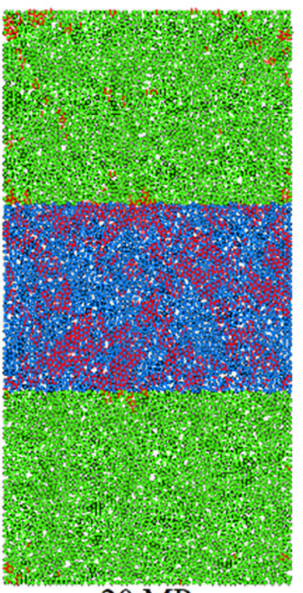

$20 \mathrm{MPa}$

(c) RMR

Fig. 13 Numerical failure modes of a coal-rock composite specimen 

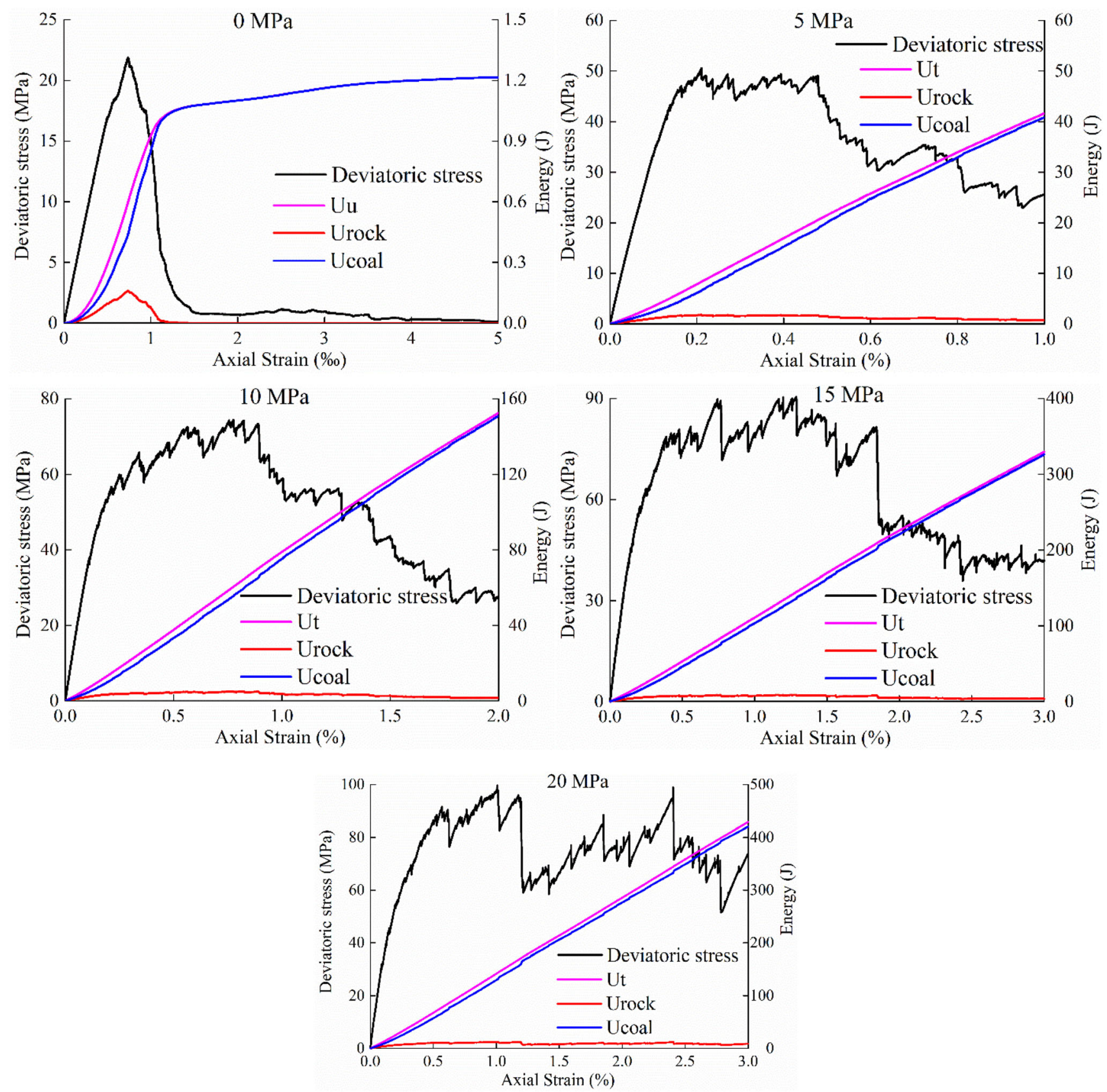

(a) MR

Fig. 14 Evolution of the strain energy of both coal and rock

(2) The failure of the coal-rock composites acted upon by various levels of confining pressure occurs frequently in the coal because of its low strength, affecting the stability of roadways.
(3) In accordance with micro and macro failures of specimens, the cracking in the coal is restrained by increasing the confining pressure. The confining 

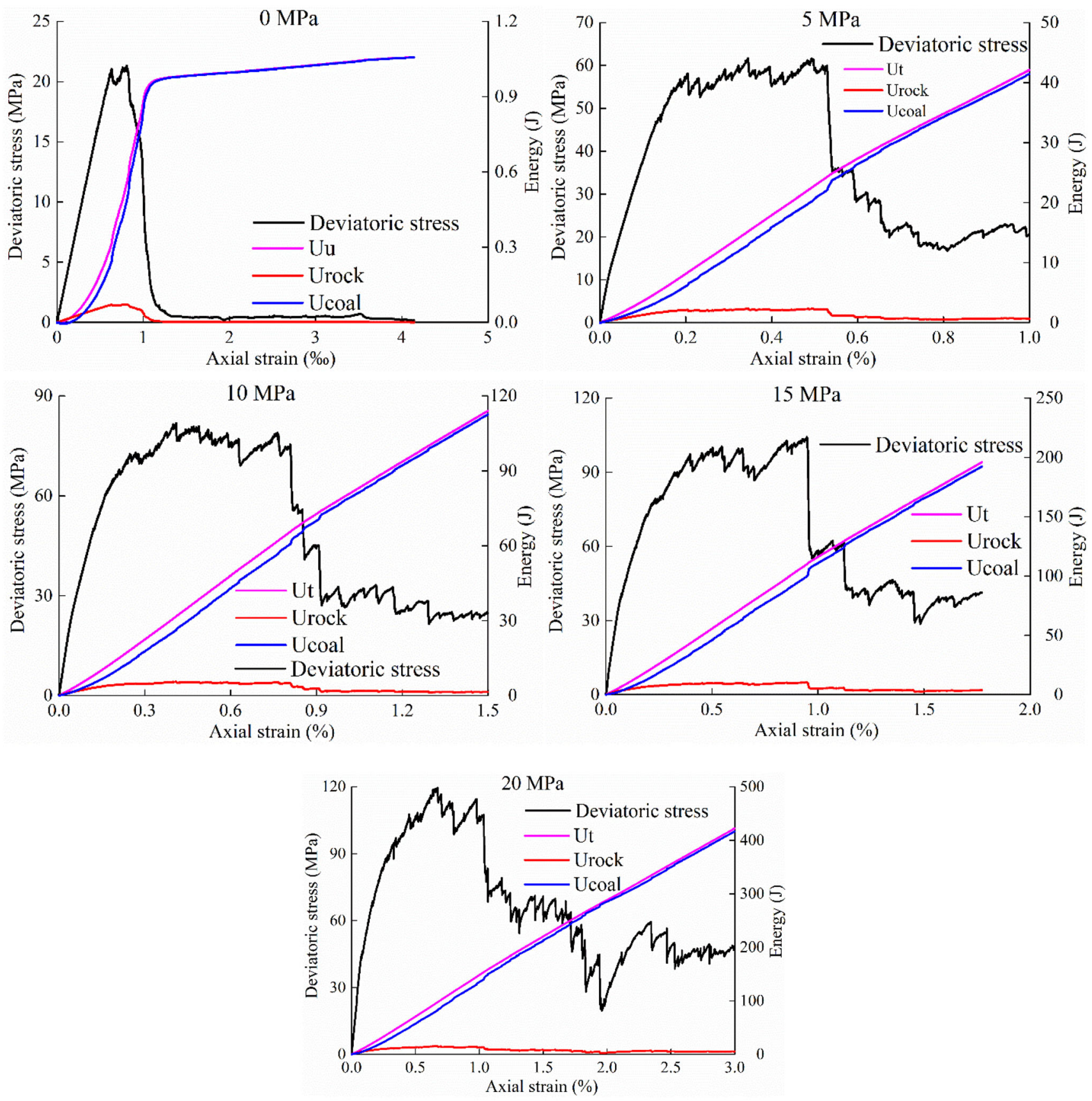

(b) RM

Fig. 14 continued 

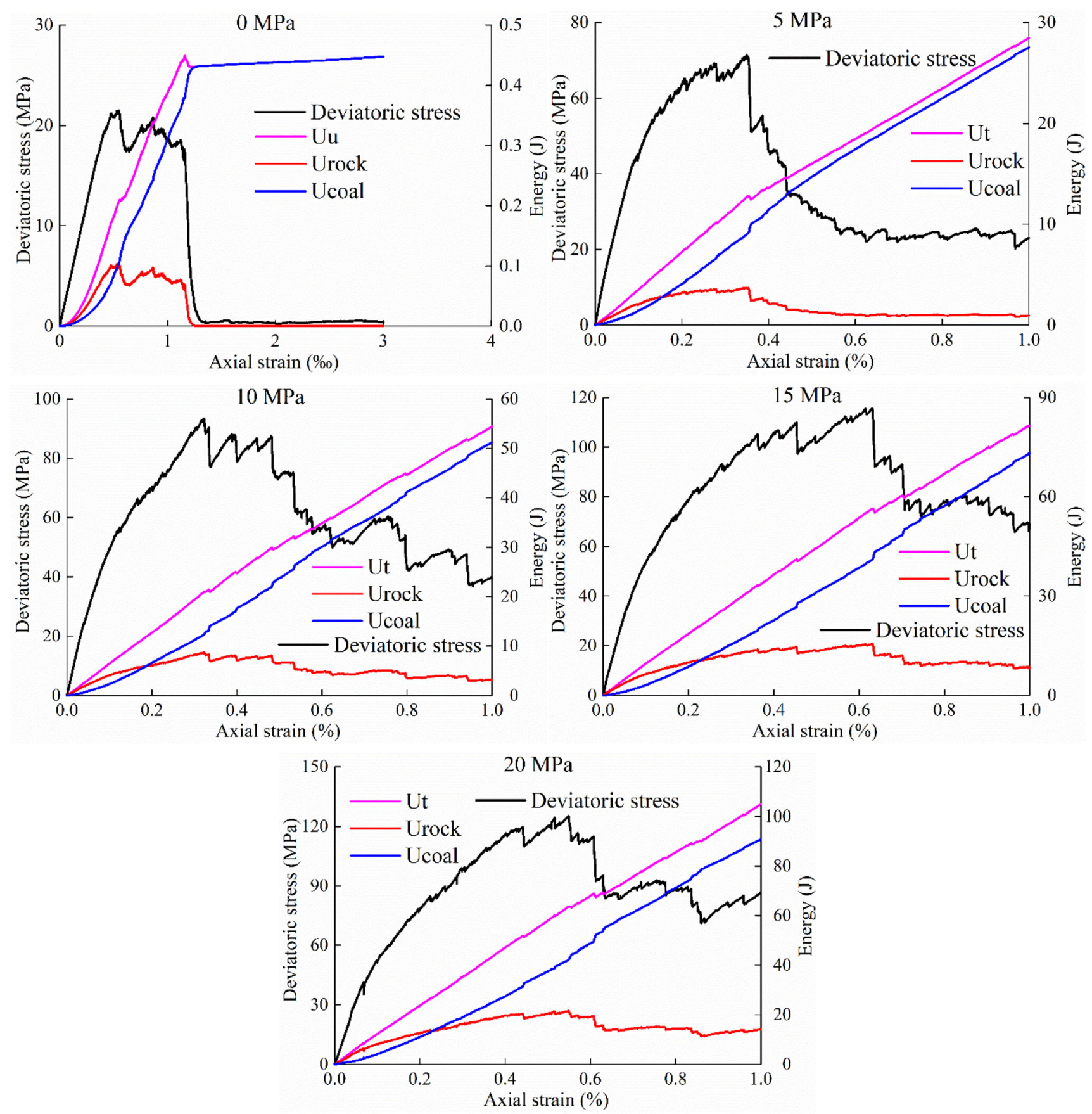

(c) RMR

Fig. 14 continued 


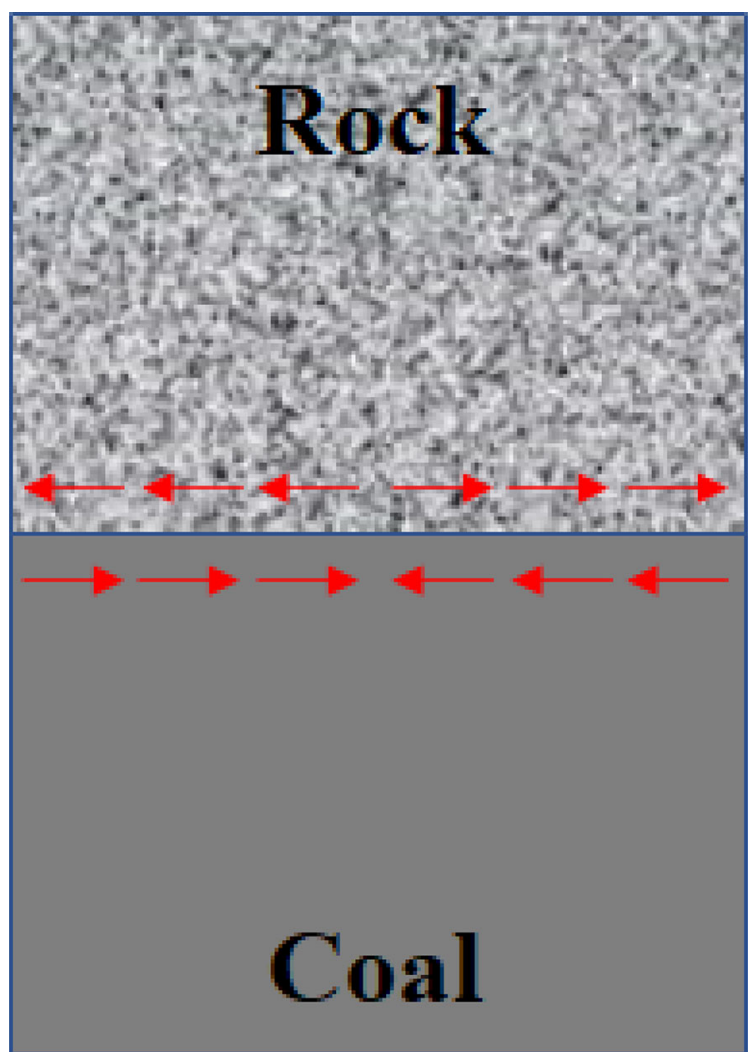

Fig. 15 Stress state of coal and rock at the interface

pressure also could reduce the bursting proneness of coal-rock composite bodies.

(4) The energy is more likely to accumulate in the coal, instead of the hard rock, due to the high deformability of the coal which may be the primary carrier of energy accumulation. During the mining process, a rockbust is more likely to occur in a coal seam.

Acknowledgements This study was financially supported by Beijing Outstanding Young Scientist Program (BJJWZYJH01201911413037), National Natural Science Foundation of China (41877257; 51622404; 52009131), Shaanxi Coal Group Key Project (2018SMHKJ-A-J-03) and Yueqi outstanding scholar Award Program by CUMTB.

\section{Compliance with ethical standards}

Conflict of interest The authors wish to confirm that there are no known conflicts of interests associated with this publication and there has been no significant financial support for this work that could have influenced its outcome.

Open Access This article is licensed under a Creative Commons Attribution 4.0 International License, which permits use, sharing, adaptation, distribution and reproduction in any medium or format, as long as you give appropriate credit to the original author(s) and the source, provide a link to the Creative Commons licence, and indicate if changes were made. The images or other third party material in this article are included in the article's Creative Commons licence, unless indicated otherwise in a credit line to the material. If material is not included in the article's Creative Commons licence and your intended use is not permitted by statutory regulation or exceeds the permitted use, you will need to obtain permission directly from the copyright holder. To view a copy of this licence, visit http://creativecommons. org/licenses/by/4.0/.

\section{References}

Bahrani N, Kaiser PK (2013) Strength degradation of non-persistently jointed rockmass. Int J Rock Mech Min Sci 62:28-33

Bieniawski ZT (1984) Rock mechanics design in mining and tunneling. A.A. Balkema Publications, Rotterdam

Cai W, Dou LM, Si GY, Cao AY, He J, Liu S (2016) A principal component analysis/fuzzy comprehensive evaluation model for coal burst liability assessment. Int $\mathrm{J}$ Rock Mech Min Sci $81: 62-69$

Chen YL, Zuo JP, Liu DJ, Wang ZB (2019) Deformation failure characteristics of coal-rock combined body under uniaxial compression: experimental and numerical investigations. Bull Eng Geol Environ 78:3449-3464

Chen YL, Teng JY, Sadiq RAB, Zhang K (2020) Experimental study of bolt-anchoring mechanism for bedded rock mass. Int $\mathbf{J}$ Geomech 20(4):04020019

Dou LT, Yang K, Chi XL (2020) Fracture behavior and acoustic emission characteristics of sandstone samples with inclined precracks. Int J Coal Sci Technol. https://doi.org/10.1007/ s40789-020-00344-X

Guo ZB, Wang Q, Yin SY, Kuai XH, Yan DS, Li MY, Qu YD (2019) The creep compaction behavior of crushed mudstones under the step loading in underground mining. Int $\mathrm{J}$ Coal Sci Technol 6(3):408-418

Ju Y, Sun HF, Xing MX, Wang XF, Zheng JT (2018) Numerical analysis of the failure process of soil-rock mixtures through computed tomography and PFC3D models. Int J Coal Sci Technol 5(2):126-141

Kim BH, Walton G, Larson MK, Berry S (2020) Investigation of the anisotropic confinement-dependent brittleness of a Utah coal. Int J Coal Sci Technol. https://doi.org/10.1007/s40789-020-00364-7

Li HG, Li HM (2017) Mechanical properties and acoustic emission characteristics of thick hard roof sandstone in Shendong coal field. Int J Coal Sci Technol 4(2):147-158

Li CY, Zuo JP, Wei CC, Xu X, Zhou ZQ, Li Y, Zhang Y (2020) Fracture development at laminated floor layers under longwall face in deep coal mining. Nat Resour Res 29:3857-3871

Lian XG, Hu HF, Li T, Hu DS (2020) Main geological and mining factors affecting ground cracks induced by underground coal mining in Shanxi Province, China. Int J Coal Sci Technol 7(2):362-370

Liu J, Wang EY, Song DZ, Wang SH, Niu Y (2015) Effect of rock strength on failure mode and mechanical behavior of composite samples. Arab J Geosci 8:4527-4539

Long LF, Li ZP (2018) A numerical study on dynamics of cavity growth in nonlinear elasticity. Int J Fract 214(2):103-113

Lu W, Wang Q, Jiang B, Xu S, Liu B, Zhang P, Jiang ZH (2019) Comparative study on bearing mechanism and design parameters of confined concrete arch joints in deep soft rock roadway. Int $\mathbf{J}$ Coal Sci Technol 6(4):493-504

National Standards of the People's Republic of China (2010a) Methods for test, monitoring and prevention of rock burst-Part 2: Classification and laboratory test method on bursting liability of coal. In: GB/T25217.2-2010. Standardization Administration of China, Beijing 
National Standards of the People's Republic of China (2010b) GB/T 25217.2-2010. Methods for test,monitoring and prevention of rock burst-prt 2: classification and laboratory test method on bursting liability of coal

Nikolenko PV, Epshtein SA, Shkuratnik VL, Anufrenkova PS (2020) Experimental study of coal fracture dynamics under the influence of cyclic freezing-thawing using shear elastic waves. Int $\mathrm{J}$ Coal Sci Technol. https://doi.org/10.1007/s40789-020-00352-x

Peng J, Rong G, Cai M, Wang XJ, Zhou CB (2014) An empirical failure criterion for intact rocks. Rock Mech Rock Eng 47(2):347-356

Qu RT, Zhang ZF (2018) Failure surfaces of high-strength materials predicted by a universal failure criterion. Int J Fract 211:273-252

Shen JY, Zhan SX, Karakus M, Zuo JP (2020) Effects of flaw width on cracking behavior of single-flawed rock specimens. Bull Eng Geol Environ. https://doi.org/10.1007/s10064-020-02029-w

Singh SP (1988) Burst energy release index. Rock Mech Rock Eng 21:149-155

Vodička R, Kormaníková E, Kšiňan F (2018) Interfacial debonds of layered anisotropic materials using a quasi-static interface damage model with Coulomb friction. Int J Fract 211:163-182

Wang HW, Jiang YD, Xue S, Pang XF, Lin ZN, Deng DX (2017a) Investigation of intrinsic and external factors contributing to the occurrence of coal bumps in the mining area of western Beijing, China. Rock Mech Rock Eng 50(4):1033-1047

Wang K, Du F, Zhang X, Wang L, Xin CP (2017b) Mechanical properties and permeability evolution in gas-bearing coal-rock combination body under triaxial conditions. Environ Earth Sci 76:815

Wang BN, Dang FN, Chao W, Miao YP, Li J, Chen F (2019) Surrounding rock deformation and stress evolution in pre-driven longwall recovery rooms at the end of mining stage. Int $\mathrm{J}$ Coal Sci Technol 6(4):536-546

Wang JT, Zuo JP, Sun YJ, Wen JH (2020) The effects of thermal treatments on the fatigue crack growth of Beishan granite: An in situ observation study. Bull Eng Geol Environ. https://doi.org/ 10.1007/s10064-020-01966-w

William FH (2013) Solid mechanics. Cambridge University Press, Cambridge

Wu X, Peng YW, Xu J, Yan Q, Nie W, Zhang TT (2020) Experimental study on evolution law for particle breakage during coal and gas outburst. Int J Coal Sci Technol 7(1):97-106

Xie HP, Li L, Peng R, Ju Y (2009) Energy analysis and criteria for structural failure of rocks. J Rock Mech Geotech Eng 1(1):11-20

Xue DJ, Zhou J, Liu YT, Gao L (2020) On the excavation-induced stress drop in damaged coal considering a coupled yield and failure criterion. Int J Coal Sci Technol 7(1):58-67

Yang SQ, Jing HW (2013) Evaluation on strength and deformation behavior of red sandstone under simple and complex loading paths. Eng Geol 164:1-17

Yang SQ, Jing HW, Wang SY (2012) Experimental investigation on the strength, deformability, failure behavior and acoustic emission locations of red sandstone under triaxial compression. Rock Mech Rock Eng 45(4):583-606

Yuan RF, Shi BW (2018) Acoustic emission activity in directly tensile test on marble specimens and its tensile damage constitutive model. Int J Coal Sci Technol 5(3):295-304

Zhang S, Tang H, Zhan H, Lei G, Cheng H (2015) Investigation of scale effect of numerical unconfined compression strengths of virtual colluvial-deluvial soil-rock mixture. Int J Rock Mech Min Sci 77:208-219

Zhang HW, Elsworth D, Wan ZJ (2018) Failure response of composite rock-coal samples. Geomech Geophys Geo-energ Geo-resour 4:175-192

Zhao ZH, Wang WM, Wang LH, Dai CQ (2015) Compression-shear strength criterion of coal-rock combination model considering interface effect. Tunn Undergr Sp Tech 47:193-199

Zhao B, Wen GC, Sun HT, Sun DL, Yang HM, Cao J, Dai LC, Wang B (2018) Similarity criteria and coal-like material in coal and gas outburst physical simulation. Int $\mathrm{J}$ Coal Sci Technol 5(2):167-178

Zhao Y, Zhou HW, Zhong JC, Liu D (2019) Study on the relation between damage and permeability of sandstone at depth under cyclic loading. Int J Coal Sci Technol 6(4):479-492

Zuo JP, Pei JL, Liu JF, Peng R, Li YC (2011a) Investigation on acoustic emission behavior and its time-space evolution mechanism in failure process of coal-rock combined body. Chin $\mathrm{J}$ Rock Mech Eng 30(8):1564-1570 (in Chinese)

Zuo JP, Xie HP, Wu AM, Liu J (2011b) Investigation on failure mechanisms and mechanical behaviors of deep coal-rock single body and combined body. Chin J Rock Mech Eng 30(1):84-92 (in Chinese)

Zuo JP, Wang ZF, Zhou HW, Pei JL, Liu JF (2013) Failure behavior of a rock-coal-rock combined body with a weak coal interlayer. Int J Min Sci Tech 23:907-912

Zuo JP, Chen Y, Zhang JW, Wang JT, Sun YJ, Jiang GH (2016) Failure behavior and strength characteristics of coal-rock combined body under different confining pressures. J China Coal Soc 41:2706-2713 (in Chinese)

Zuo JP, Wang JT, Jiang YQ (2019) Macro/meso failure behavior of surrounding rock in deep roadway and its control technology. Int J Coal Sci Technol 6(3):301-319

Zuo JP, Song HQ, Jiang YQ, Zhao SK, Yu ML, Li LY (2020a) Preliminary discussion on comprehensive research method for rock burst in coal mine based on Newton's second law. Shock Vib 2020:8861306

Zuo JP, Yu ML, Li CY, Sun YJ, Hu SY, Li ZD (2020b) Analysis of surface cracking and fracture behavior of a single thick main roof based on similar model experiments in western coal mine, China. Nat Resour Res. https://doi.org/10.1007/s11053-02009735-y

Zuo JP, Wei X, Shi Y, Liu C, Li M, Wong RHC (2020c) Experimental study of the ultrasonic and mechanical properties of a naturally fractured limestone. Int J Rock Mech Mining Sci $125: 104162$ 